Review

\title{
From conventional sensors to fibre optic sensors for strain and force measurements in biomechanics applications: A review
}

\author{
Paulo Roriz ${ }^{\mathrm{a}, \mathrm{b}}$, Lídia Carvalho ${ }^{\mathrm{a}, \mathrm{b}, *}$, Orlando Frazão ${ }^{\mathrm{b}}$, José Luís Santos ${ }^{\mathrm{b}}$, \\ José António Simões ${ }^{a}$ \\ a Centre for Mechanical Technology and Automation (TEMA), Department of Mechanical Engineering, University of Aveiro, Campus Universitário de Santiago, \\ 3810-193 Aveiro, Portugal \\ ${ }^{\mathrm{b}}$ INESC-Porto and Faculty of Sciences of the University of Porto (FCUP), Rua do Campo Alegre, 687, 4150-179 Porto, Portugal
}

\section{A R T I C L E I N F O}

Article history:

Accepted 25 January 2014

\section{Keywords:}

Fibre optical sensors

Biomechanics

Strain

Force

In vivo sensing

\begin{abstract}
A B S T R A C T
In vivo measurement, not only in animals but also in humans, is a demanding task and is the ultimate goal in experimental biomechanics. For that purpose, measurements in vivo must be performed, under physiological conditions, to obtain a database and contribute for the development of analytical models, used to describe human biomechanics. The knowledge and control of the mechanisms involved in biomechanics will allow the optimization of the performance in different topics like in clinical procedures and rehabilitation, medical devices and sports, among others.

Strain gages were first applied to bone in a live animal in 40's and in 80's for the first time were applied fibre optic sensors to perform in vivo measurements of Achilles tendon forces in man.

Fibre optic sensors proven to have advantages compare to conventional sensors and a great potential for biomechanical and biomedical applications. Compared to them, they are smaller, easier to implement, minimally invasive, with lower risk of infection, highly accurate, well correlated, inexpensive and multiplexable.

The aim of this review article is to give an overview about the evolution of the experimental techniques applied in biomechanics, from conventional to fibre optic sensors. In the next sections the most relevant contributions of these sensors, for strain and force in biomechanical applications, will be presented. Emphasis was given to report of in vivo experiments and clinical applications.
\end{abstract}

(c) 2014 Elsevier Ltd. All rights reserved.

\section{Contents}

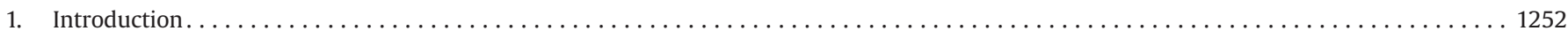

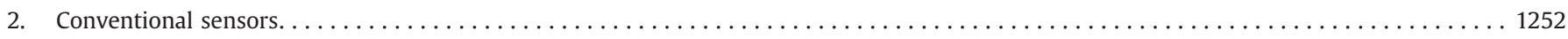

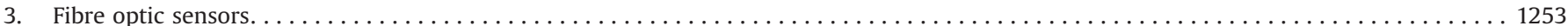

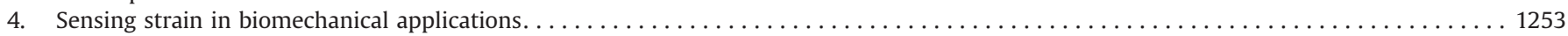

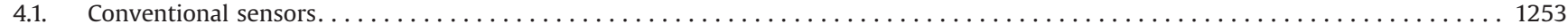

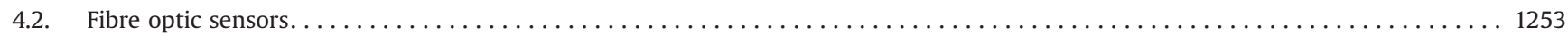

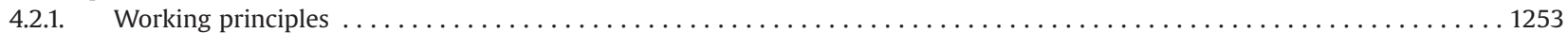

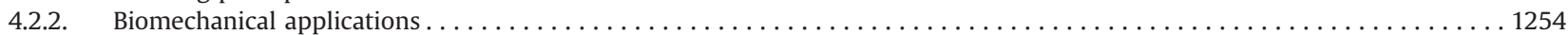

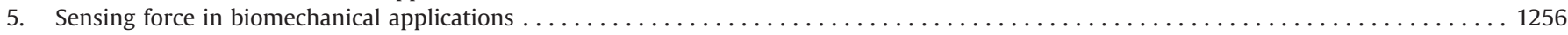

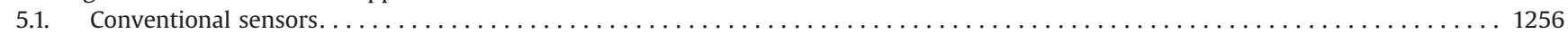

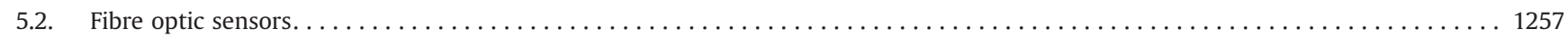

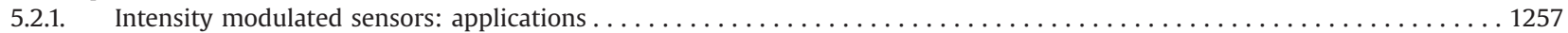

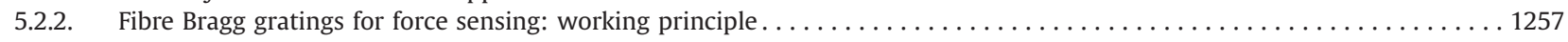

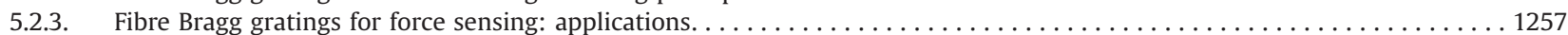

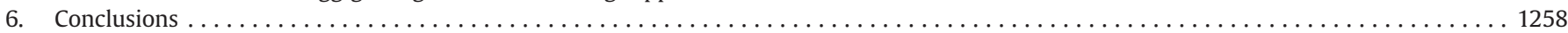

\footnotetext{
* Corresponding author at: INESC-Porto and Faculty of Sciences of the University of Porto (FCUP), Rua do Campo Alegre, 687, 4150-179 Porto, Portugal.

Tel.: + 351220402 301; fax: +351220402437.

E-mail address: lidiacarvalho@ua.pt (L. Carvalho).
} 


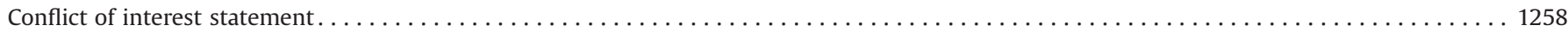

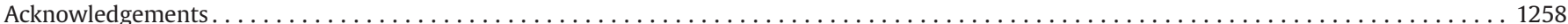

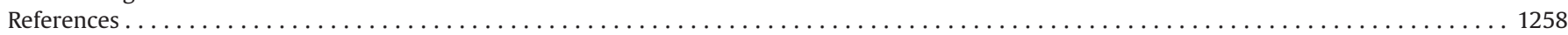

\section{Introduction}

In vivo measurement, not only in animals but also in humans, is a demanding task and is the ultimate goal in experimental biomechanics. Even for finite element analysis in biomechanics, results must be validated with experimental ones, as also biological materials properties and load conditions must be obtained. For that purpose, measurements in vivo must be performed, under physiological conditions, to obtain a database and contribute for the development of analytical models, used to describe human biomechanics. The knowledge and control of the mechanisms involved in biomechanics will allow the optimization of the performance in different topics like in clinical procedures and rehabilitation, medical devices and sports, among others.

In biomechanics, strain and strain rate are the most important parameters used to characterize any biological system and its interactions with biomedical devices. For instance, it is well established that bone osteogenesis and bone remodelling process is a strain guided process. In that mechanism, muscular contraction forces are the most important contributors to bone strain patterns. Until now, there is no accurate process to measure that kind of forces, even by electromyography. Therefore, mere estimations of bone deformation by assessment of external loading and inverse dynamics approach cannot provide a full account of the relationship between bone strains and osteogenic bone response. Although the importance of bone strain for bone metabolism has been well established, knowledge of in vivo bone strains, during habitual physical activities and specific exercises, is very limited (Yang et al., 2011). Strain gages were first applied to bone in a live animal in 40's (Caler et al., 1981)and in 80's (Komi et al., 1984) applied for the first time fibre optic sensors (FOS) to perform in vivo measurements of Achilles tendon forces in man.

The characterization of soft tissues properties like skin, organs or tendons is also important in biomechanics. More recently, 3D image correlation is a full-field optical measuring techniques and has great advantages like being a non-contact and full-field technique; it is possible to visualize strain gradients and $3 \mathrm{D}$ details; it is possible to test non-homogeneous and anisotropic materials; viability to study tissues and organs, in vitro or in vivo (Tyson et al., 2002).

To the best of our knowledge, it was found few recent review articles, where it has been discussed FOS sensing technology applications in biomechanics (Mishra et al., 2011; Al-Fakih et al., 2012; Roriz et al., 2013a, 2013b). In another review article, performed by Zawawi et al. (2013), it is presented an extensive an comparative review on the implementation of optical fibre intensity sensors, specifically for clinical health monitoring applications, including lumbar spine monitoring, upper and lower limb, motion tracking, as well as respiration state and heartbeat assessment. The authors also presented the advantages and limitations between optical fibre intensity modulated sensor and non-optical sensor types for each application are compared.

The aim of this review article is to give an overview about the evolution of the experimental techniques applied in biomechanics, from conventional to FOS. In the next sections the most relevant contributions of these sensors, for strain and force in biomechanical applications, will be presented. Emphasis was given to report of in vivo experiments and clinical applications.

\section{Conventional sensors}

Conventional sensors (CS) applied in biomechanical applications are based on piezoresistive, strain gauge (SG) or other solidstate sensing technologies. They represent a highly tested, mature and overspread technology, offering good sensitivity, precise measurements and competitive price. However, their miniaturization, typically requiring sensor head diameters below $0.5 \mathrm{~mm}$, such as for minimally invasive procedures, presents some drawbacks. Mignani and Baldini (1996) have pointed some of them, including fragility, long term instability, inconsistency and excessive drift. Additionally, their output is restricted to a small sensing area making it necessary to use more sensors to sense larger regions, but only at the expense of increased dimensions and loss of flexibility (Arkwright et al., 2009). These disadvantages combined with poor biocompatibility of metallic components and large sensitivity to EM interference, can compromise some in vivo applications and their use in clinical practice. As pointed by Ladd and Quick (2000) ferromagnetic based sensors should not be used in magnetic resonance imaging (MRI) because they will act as an antenna and generate significant heating effects, which might cause image artefacts.

Different methods have been used to measure bone deformation under load, including SG (Szivek and Gharpuray, 2000), extensometer (Perusek et al., 2001), ultrasound (Vlannderen et al., 2005) and echo tracking (Matsuyama et al., 2006). The SG is the gold standard for measuring bone deformation in vivo (Lanyon et al., 1975; Szivek et al., 2005). It has been used in a variety of animal studies (De Smet et al., 2008) and, also, few strain measurements in humans have been reported, namely on the tibia during normal and vigorous activity (Lanyon et al., 1975; Burr et al., 1996) and to detect spine fusion (Szivek et al., 2002, 2005).

The liquid metal strain gauge (LMSG) transducer, introduced in 50's (Whitney, 1953), also known as the implanted mercury-insilastic SG, has been extensively used to assess strain in soft tissues. The sensor is well described in the work of Ravary et al. (2004) and was applied for ex vivo studies of knee ligaments (Whitney, 1953; Edwards et al., 1970; Kennedy et al., 1977; Draganich and Vahey, 1990; Berns et al., 1992; Hull et al., 1996; Bach et al., 1997). To the best of our knowledge, in vivo studies were performed with animal specimens only, namely in soft tissues (Brown et al., 1986; Keegan et al., 1992; van Weeren et al., 1992; Jansen et al., 1998) and bone (Haussler et al., 2001). The possibility of disruption of the silastic tube and release of toxic liquid, such as mercury, suggests caution for human in vivo procedures (Ravary et al., 2004). Other important limitations include a relatively small service life due to porosity of the silastic tube, failure of wire connections (Brown et al., 1986; Ravary and Pourcelot et al., 2004) and inflammatory reactions (Brown et al., 1986; Jansen et al., 1998).

For magnetic field based sensors, the HEST and the DVRT (MicroStrain Inc.) have been used to assess strain on ligaments and tendons either ex vivo (Fleming, 1994; Markolf et al., 1998) and in vivo (Erickson et al., 1988; Beynnon et al., 1992; Beynnon and Fleming, 1998; Fleming et al., 2001; Fleming et al., 2002). More recent than HEST, the DVRT exhibits a better performance (Beynnon and Fleming, 1998). Their implantation requires intra-articular anaesthesia (Beynnon et al., 1992; Fleming and Beynnon, 2004). 
No significant patient adverse reactions due to surgical or experimental procedures have been reported (Beynnon et al., 1992; Fleming and Beynnon, 2004). Providing only localized measurements of strain they make it difficult to correlate strain with the total force in the ligament or tendon (Markolf et al., 1990). Theoretically, it is possible to map strain distribution in soft tissues using multiple DVRT but it requires further miniaturization (Fleming and Beynnon, 2004). The DVRT shall not be used in activities where knee joint is near full extension, such as gait and jumping, due to impinging against the roof of the intercondylar notch (Fleming and Beynnon, 2004).

\section{Fibre optic sensors}

FOS were introduced in the 60's, mainly for endoscopic, intravascular and cardiac applications (Hopkins and Kapany, 1954; Enson, et al., 1962; Polanyi and Hehir 1962; Enson et al., 1964; Clark et al., 1965; Frommer et al., 1965; Gamble et al., 1965; Hugenholtz et al., 1965; Harrison et al., 1966; McCarthy et al., 1967; Mook et al., 1968; Hugenholtz et al., 1969; Lekholm and Lindström, 1969; Ramirez et al., 1969; Singh et al., 1970). FOS are characterized by their high sensitivity when compared to other types of sensors. They present some interesting advantages such as compactness, geometric versatility, inertness and biocompatibility, immunity to electromagnetic noise and low cost.

The most common working principles applied to FOS for biomedical and biomechanical applications are based on intensity, phase and wavelength modulation, the latter associated with the operation of fibre Bragg gratings (FBG). Intensity modulated sensors were introduced in the early 60's (Enson et al., 1962; Polanyi and Hehir, 1962; Enson et al., 1964; Clark et al., 1965; Frommer et al., 1965; Gamble et al., 1965; Hugenholtz et al., 1965; Harrison et al., 1966; McCarthy et al., 1967; Mook et al., 1968; Hugenholtz et al., 1969; Lekholm and Lindström, 1969; Ramirez et al., 1969; Singh et al., 1970). Some possible configurations have been described (Silvestri and Schena, 2011). Interferometric based sensors also made several configurations possible (e.g., Sagnac interferometer, Michelson interferometer, Mach-Zehnder interferometer), but the Fabry-Pérot (F-P) interferometer (Fabry and Pérot, 1896) has been the most applied in minimally invasive sensors. F-P interferometer sensors were introduced in the early 80 's and solved many drawbacks of intensity modulated sensors. Instead of measuring a change in light intensity, it's measured phase differences in the light beams. A small-size sensing element is bonded to the tip of the fibre and consists in an optical cavity, formed by two parallel reflecting surfaces, one of which is a diaphragm that changes the optical cavity depth, under the action of the measurand. Compared to intensity modulated schemes and FBG sensors, F-P interferometers are capable to achieve high sensitivities and resolutions, but at the expense of relatively complex interrogation techniques (Yu and Shizhuo, 2002).

Wavelength modulation is achieved through use of FBG sensors which are probably the simplest and most interesting type of FOS. FBG can be used for detecting strain in bones, pressure mapping in orthopaedic joints, stresses in intervertebral discs, chest wall deformation, forces induced by tendons and ligaments, angles between body segments during gait. However, their use in the field of biomechanics and rehabilitation applications is very recent and its practicality for full-scale implementation has not yet been fully established (Mishra et al., 2011; Al-Fakih et al., 2012). Despite FBG sensors being a strong candidate to be used for in vivo bone applications only in a recent study performed by Lídia Carvalho et al., (2011), its response to bone cells and its sensing capability was studied. Results showed excellent osteoblastic cytocompatibility and FBG maintained the physical integrity and functionality, as its sensing capability was not affected. Karam et al. (2011) have evaluated the efficacy of different processes for the decontamination and sterilization of FBG. Fibre optic samples, were contaminated by E. coli and S. aureus and were sterilized by autoclave heating, immersion in ethylene oxide, sodium hypochlorite, chloramines $\mathrm{T}$ or peracetic acid and illumination ultra-violet radiation. The sterilization practices by heating and immersion avoided the formation of bacteria colonies, while illumination processes was not effective.

\section{Sensing strain in biomechanical applications}

\subsection{Conventional sensors}

Besides previous presented applications, a wide variety of electrical SG sensors were used to assess strain in body tissues, mainly in bone (Barnes and Pinder, 1974; Lanyon et al., 1975; Aamodt et al., 1997; Hoshaw et al., 1997; Arndt et al., 1999; Milgrom et al., 2000; Szivek et al., 2002; Milgrom et al., 2004). The SG was considered to be the gold standard for measuring deformation in bone (Fresvig et al., 2008).

For the moment, two in vivo studies making use of SG have been applied to measure ligament and tendon forces. The first one is the original study of Barnes and Pinder (1974) in which strain was measured in the metacarpal bone of horse. From comparison of large and small foil resistance SG sensors, valid results were possible to obtain with those covering $1 \mathrm{~mm}^{2}$ of bone surface (Barnes and Pinder, 1974). Following earlier in vivo studies (Lanyon et al., 1975; Burr et al., 1996), tibial strains were measured with micro SG (Rolf et al., 1997; Milgrom et al., 2000). No pre or postsurgery complications were reported, but the implantation technique seems too complicated to be applied. One subject reported a deep sensation of pain due to drilling of cortical bone and was also reported problems in the attachment of the transducer (Rolf et al., 1997).

\subsection{Fibre optic sensors}

FOS, namely FBG sensors, seems to be in good position to substitute the above strain sensors. Compared to them, they are easier to implement, minimally invasive, with lower risk of infection, highly accurate, inexpensive and multiplexable (Rao et al., 1997; Erdemir et al., 2002). Moreover, FBG sensors have a linear response to axial strain and provide direct and absolute measurements (Othonos, 1997; Fresvig et al., 2008). Nevertheless, few applications with FBG sensors are known to assess strain in soft tissues.

\subsubsection{Working principles}

FBG is an optical sensor recorded within the core of a standard optical fibre. It reflects a narrow bandwidth of light which responds faithfully to strain and temperature. A Bragg grating can be defined as a periodic perturbation of the refractive index of the fibre core. When a FBG is illuminated by a broadband light source, the reflected spectrum is centred at the Bragg wavelength $\left(\lambda_{B}\right)$ (Fig. 1). The Bragg grating wavelength can be calculated as:

$\lambda_{B}=2 n \Lambda$

where $n$ is the effective refractive index and $\Lambda$ is the grating pitch. The shift of the grating optical reflection spectrum $\left(\Delta \lambda_{B}\right)$ is related to mechanical load or thermal variations of a FBG and permits great resolution, precision and adequate dynamic range for applications, like in biomechanics, and can be calculated according 

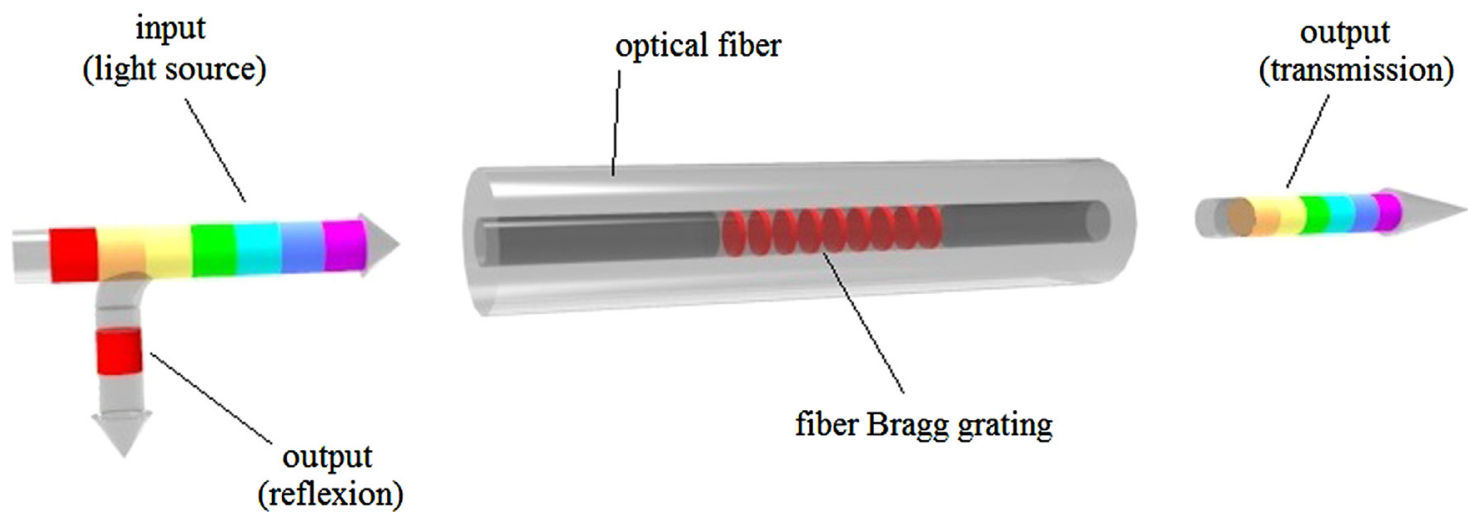

(reflexion)

fiber Bragg grating

Fig. 1. Schematic representation of the fibre Bragg grating sensor.

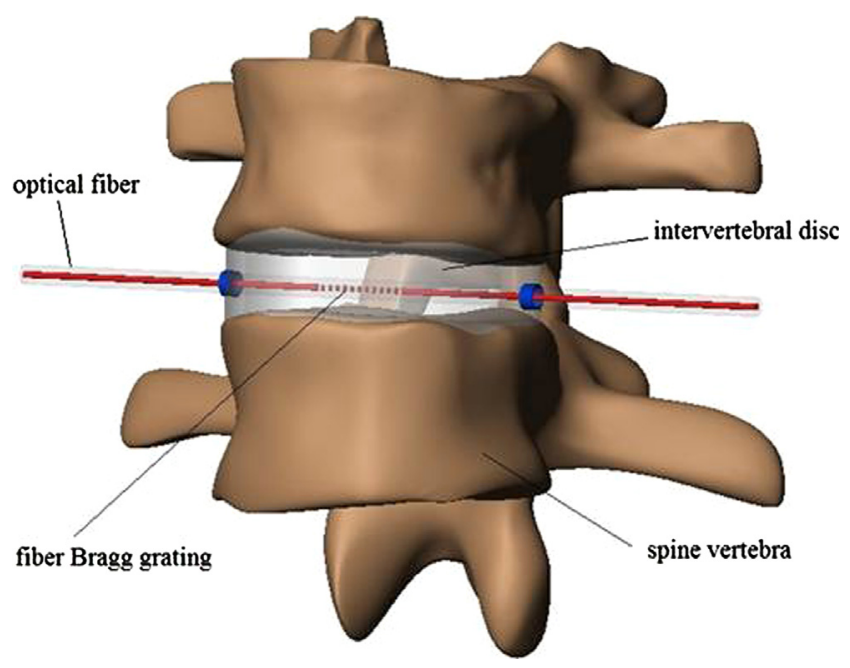

Fig. 2. Schematic representation of the fibre Bragg grating sensor used to measure intervertebral disc bulging under compression (Roriz et al., 2011).

with Eq. (2):

$\Delta \lambda_{B}=2\left(\Lambda \frac{\partial n_{e f f}}{\partial \varepsilon}+n_{e f f} \frac{\partial \Lambda}{\partial \varepsilon}\right) \Delta \varepsilon_{z}+2\left(\Lambda \frac{\partial n_{e f f}}{\partial T}+n_{e f f} \frac{\partial \Lambda}{\partial T}\right) \Delta T$

The first term represents the strain dependence on the Bragg wavelength variation and the second term, the thermal effect on the same parameter. Eq. (2) shows that an FBG can be employed as a sensor-element, by monitoring the back reflected light from the Bragg grating, for longitudinal mechanical strain, $\varepsilon_{z}$, and temperature, $T$. For dynamic mechanical loads, the thermal contribution can be neglected and the sensibility of an FBG to $\varepsilon_{z}$, is given by Eq. (3):

$\frac{\Delta \lambda_{B}}{\lambda_{B}}=\left\{\left(1-\left(\frac{n^{2}}{2}\right)\right)\left[p_{12}-\nu\left(p_{11}+p_{12}\right)\right]\right\} \varepsilon_{z}$

where $\nu$ and $p_{\mathrm{ij}}$ are mechanical properties of cladding material. Eq. (3) can be simply written as:

$\frac{\Delta \lambda_{B}}{\lambda_{B}}=\left(1-p_{e}\right) \varepsilon_{z}$

where $p_{e}$ is the effective strain-optic coefficient of the fibre. Because the Bragg wavelength is directly proportional to the grating period a shift in the Bragg wavelength will be observed making possible to monitor the induced strain (Othonos, 1997). The sensitivities for strain and temperature of a FBG recorded at $1550 \mathrm{~nm}$ are approximately $1.2 \mathrm{pm} \mu \varepsilon^{-1}$ and $13.7 \mathrm{pm}^{\circ} \mathrm{C}^{-1}$ (Othonos, 1997).

For in vivo measurements when strain values are only required, cross sensitivity of FBG to temperature must be take into account to be compensated with accurate implemented techniques (Xu et al., 1994), instead of assuming negligible effects under apparently controlled situations. That is the case for in vivo applications under infectious process or vigorous physical activity, followed by an increase in temperature, or for long term monitoring temperature corrections must be made.

\subsubsection{Biomechanical applications}

Ren et al. (2007) proposed a displacement sensor based on a FBG and shape memory alloy technology to monitor cadaveric tendon and ligament strains. Recently, Roriz et al. (2011) embedded a FBG sensor into the intervertebral disc of a cadaveric porcine spine and measured disc deformation under axial compression (Fig. 2).

FBG sensors can also contribute to map strain along the entire tissue using multiplexing techniques. This work still has to be done, but it will ensure more reliable comparisons. In fact, CS are only capable of providing an average strain output between the ligament insertion sites or between known points within the ligament mid-substance (Fleming and Beynnon, 2004). Results from both techniques cannot be compared because strain varies along the ligament (Butler et al,. 1992). Because FBG can be multiplexed, strain can be mapped along the entire length or throughout the cross section of tendons or ligaments, giving a more complete picture of the whole structure.

While few applications for soft tissues are known, many can be found for hard tissues and materials, such as bone, cartilages and dental implants. The study of Fresvig et al. (2008), was important to validate the agreement between FBG and SG measurements. Acrylic and bone samples were instrumented with eight sensors each, four FBG and four SG. Both type of sensors exhibited similar behaviour without significant differences. The standard deviation (SD) of the measurements varied the same way for both types of sensors. The Pearson correlation coefficient, $r$, between the sensors was significant at the 0.01 level (two-tailed) ranging from 0.986 to 1.0 in the acrylic sample, and from 0.629 to 0.999 in the bone sample. Strain-load linearity in the acrylic was excellent for both types of sensors because the lowest linearity was 0.996 as expressed by the coefficient of determination $\left(r^{2}\right)$. In the bone sample linearity was better than 0.998 for five of the eight sensors.

Study of dental implants and supporting tissues is a major topic in biomechanics and clinical dentistry. Carvalho et al. (2006a) studied how the mandible behaves under static and impact loads 


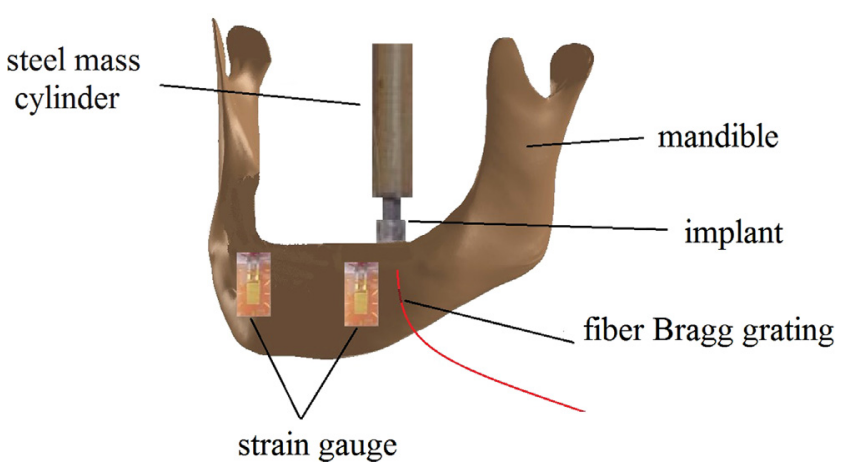

Fig. 3. Schematic representation of the fibre Bragg grating sensors and strain gage sensors used to measure bone strain at the surface of an implanted cadaveric mandible (Carvalho et al., 2006).

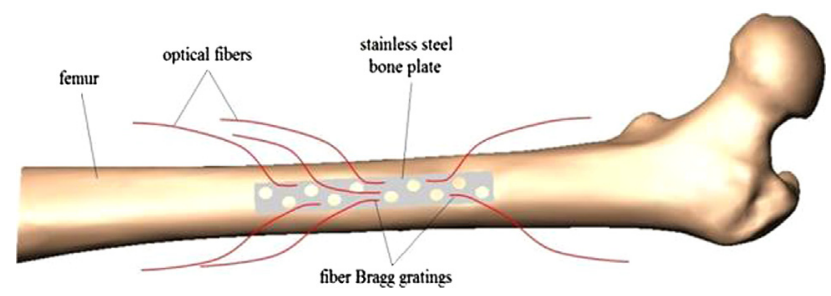

Fig. 4. Schematic drawing of fibre Bragg gratings glued to a stainless steel bone plate (Talaia et al., 2007).

acting on dental implants. FBG sensors and standard SG were glued directly to the surface of a human cadaveric mandible (Fig. 3), to measure bone strain. Besides an excellent correlation between both types of sensors, the FBG sensor was considered to be more precise in predicting load transfer from the implant to bone (Carvalho et al., 2006b). The effect of several dental implant materials, such as steel alloy, acrylonitrile butadiene styrene (ABS) and a combination of both, on the stress-strain patterns was also studied by the same research groups (Carvalho et al., 2006). A good agreement was also obtained between experimental and numerical results.

As non-conductive devices, FBG sensors can offer new applications because it is technically complex to use SG in conductive metals. In the original work of Talaia et al., (2007) seven FBG sensors were glued to stainless steel bone plates to study the effect of fracture fixation in synthetic femurs (Fig. 4). Traumatic injuries or metabolic diseases, such as osteoporosis are the most common type of bone illness affecting two hundred million individuals worldwide (Lin and Lane, 2004). FBG sensors can contribute to classify the stage of bone decalcification. First steps were taken in the in vitro experiment of Mishra et al. (2010). The strain response of bone under loading at a particular site gave a direct indication of the stiffness of bone and its degree of osteoporosis. Further studies are needed to characterize the global response of bone and to apply the technique in vivo.

Several studies have reported use of FBG sensors to monitor the curing process of dental resin cements (Ottevaere et al., 2001; Ottevaere et al., 2005; Milczewski et al., 2006; Alberto et al., 2011). To compensate temperature effects and get precise strain measurements, read-outs from two FBG sensors are necessary (Xu et al., 1994; Ren et al., 2007). One of the sensors was placed on a location of the specimen with zero mechanical strain, to sense only temperature whereas the active FBG senses both quantities. Strain can be obtained by subtracting the signal of the compensation FBG from the active one (Fig. 5).

Bone cements play an important role in the fixation of implants or prostheses and their long-term stability is a critical issue in joint biomechanics. In vitro strain and temperature characterization of

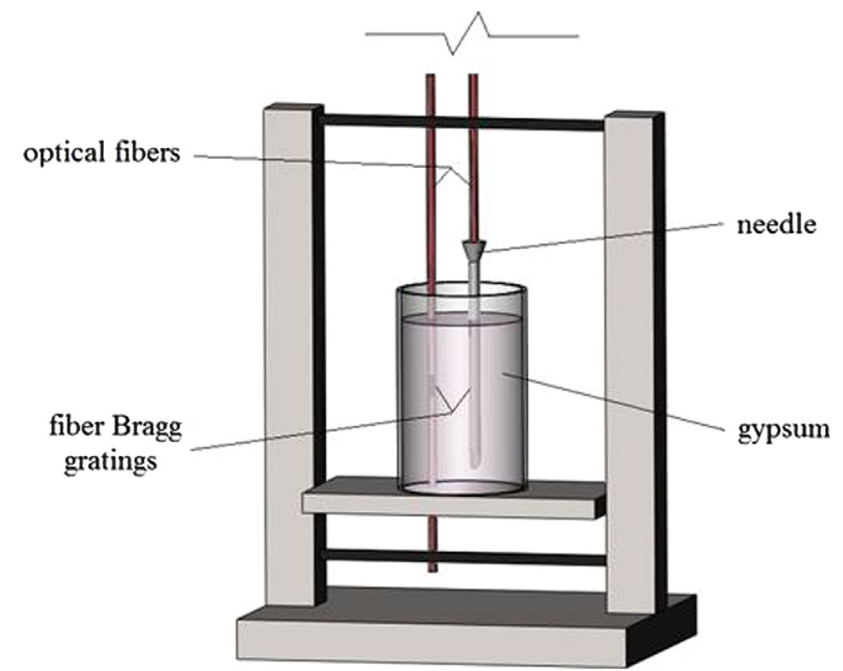

Fig. 5. Schematic representation of the setup used to measure the setting expansion and temperature variation which during the setting reaction of dental gypsum (Alberto et al., 2011).

PMMA based bone cements of femoral prostheses was studied by Frias et al. (2009) at different temperatures and load conditions, namely, those expected to occur inside the human body during locomotion. A similar study has contributed to confirm that FBG sensors are easier to implement and are less time consuming than standard SG, making them suitable for use in pre-clinical tests of prostheses and implants (Ramos et al., 2006).

Other studies made use of FBG sensors to quantify the ventilatory movements of the chest. Wehrle et al. (2001) used a fixed optical filter reference scheme with full width at half maximum of $1.5 \mathrm{~nm}$ to detect respiratory movements with frequencies up to $10 \mathrm{~Hz}$. Besides FBG sensors, intensity modulated schemes were also applied to monitor the respiratory and cardiac function. It was the case of the fibre optic plethysmography (FOP) technique. Based on macrobending losses, it consists of an expandable belt encircling the chest and a fibre optic loop that changes its radius of curvature as a function of the chest perimeter (Babchenko et al., 1999; Davis et al., 1999; Augousti et al., 2005; Augousti et al., 2006). Other FOP configurations may include long period gratings (LPG) arrays, which are more sensitive to bending (Allsop et al., 2003; Allsop et al., 2007). This technique can be applied to obtain a three dimensional geometric profile of the chest and abdomen during respiratory movements (Allsop et al., 2007). Grillet et al. (2008) used a macrobending sensor in optical fibre embedded into textile fabrics for the monitoring of respiratory movements in MRI environments (Fig. 6). A similar approach, but using an intensitymodulated microbend fibre optic sensor on light transmission, was used by Lau et al. (2013), for respiratory monitoring and respiratory gating in the MRI environment. FBG sensors were also embedded into MRI compatible needles to study their deflection (Park et al., 2008a). These preliminary investigations can contribute to improve MRI-guided percutaneous needle biopsy and brachytherapy procedures. Dziuda et al., 2013a; Dziuda et al., 2013b obtained results, using an optical strain sensor based on a fibre Bragg grating, for monitoring respiration and cardiac activity of a patient, during a magnetic resonance imaging (MRI) survey. The sensor is proposed specifically to acquire ballistocardiographic signals from a patient exposed to high intensity electromagnetic radiation. The sensor does not affect the MRI imaging quality. The applications described to measure the heartbeat sound (Gurkan et al., 2005) and blood pressure (van Brakel, 2005) from non-invasive strain measurements are also examples of the FBG technology versatility. Šprager and Zazula (2013) used 


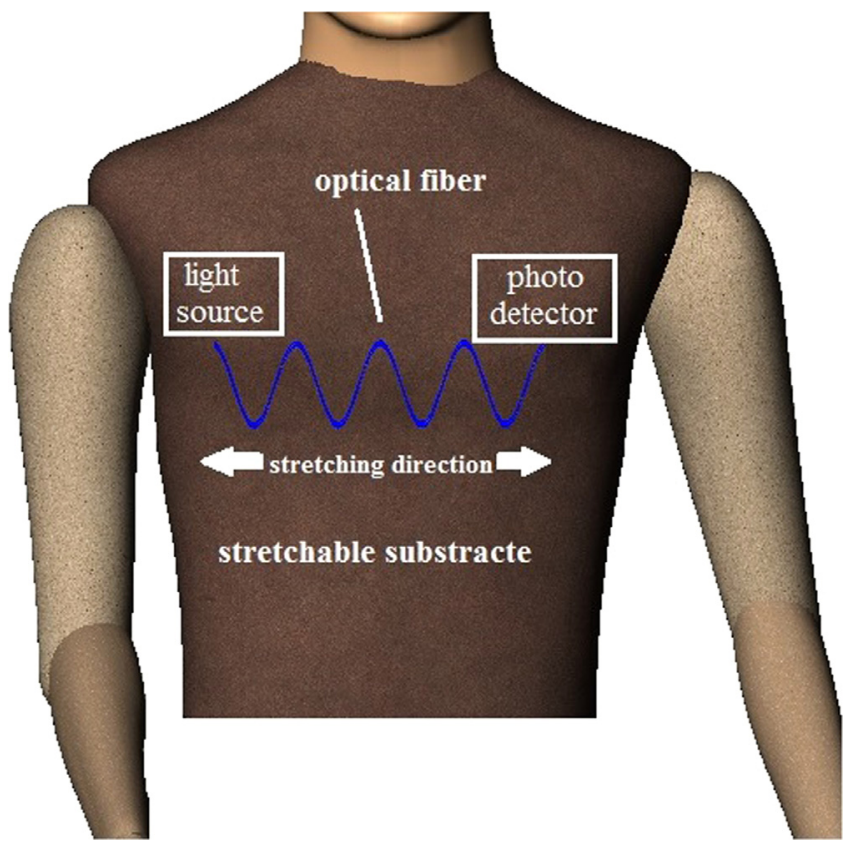

Fig. 6. Schematic drawing of macrobending sensor in optical fibre embedded into textile fabrics for the monitoring of respiratory movements (Grillet et al., 2008).

a novel approach for the detection of the heartbeat and respiration of subjects, at rest and during physical exercise. The new approach is based on the wavelet-based decomposition of the unwrapped interferometric signal, generated by length optical fibre variation, due to mechanical and acoustic activity of cardiac muscle and respiration.

Traumatic head and dental injuries can be avoided trough the use of protective devices, such as helmets and mouth guards. Studying their absorption capability like in the experiment of Tiwari et al. (2011) can contribute for new designs and material improvements. In this study, pairs of FBG sensors were bonded parallel on the mouth guard and jaw model. The mouth guard was submitted to several impact loads and the corresponding absorbed impact energy was calculated by subtracting the strain in the mouth guard from that one in the jaw.

\section{Sensing force in biomechanical applications}

\subsection{Conventional sensors}

The study of ligament or tendon/muscle forces is a main topic in medicine and sports. Ligaments resist stretch to assure the stability and congruency of a joint or a group of joints and act like joint controllers for the range of motion. Tendons connect muscle to bone transferring to them the force generated during muscle contraction. Thus, studying the forces acting in these soft tissues will contribute to understand some of their main functions. Usually, in situ forces are measured with SG based transducers. They can be inserted in the ends of insertion sites or within the mid-substance. Most of them have been designed to measure strain as the result of a compressive action on the ligament or tendon when it is stretched. Therefore, to obtain force, strain has to be converted, meaning that the calibration protocol requires special attention. There is no single or universal calibration protocol for this type of studies. Those applied before implantation of the transducer should be avoided because re-implantation leads to different results (Fleming et al., 2000). Those applied after the experiment is restricted to animal experiments because they have to be sacrificed (Holden et al., 1994). There is general agreement that calibration has to be made after implantation and the sensor must not be removed from the site where it was calibrated (Komi, 1990; Holden et al., 1995; Fleming and Beynnon, 2004). In addition, comparison of results is possible only between similar implantation sites because it has been demonstrated that the force varies along the tendon or ligament (Fleming and Beynnon, 2004). Even so, it should be taken into account that there is considerable variability between specimens making it difficult to compare results (Ahmed et al., 1987). The calibration procedure also depends on the specific characteristics of the study and this justifies the wide variety of technical resources that are being applied such as mechanical loading machines, analytical equations from cadavers, ergometer devices, equilibrium conditions from mechanics and use of pre-calibrated transducers (Komi, 1990; Holden et al., 1994; Herzog et al., 1996; Arndt et al., 1998; Fleming et al., 1999; Meyer et al., 2004).

CS used to measure ligament or tendon forces, buckle transducers, was introduced in 1969 by Salmons (1969). The frame where the SG is attached may present several different forms (Barnes and Pinder, 1974; Herrick et al., 1978; Lewis et al., 1982; An et al., 1990; Komi, 1990; Gregor et al., 1991; Miller and Robins, 1992; Fukashiro et al., 1993), a C-form (Collins et al., 1975; Henning et al., 1985), and E-form (Walmsley et al., 1978; Komi et al., 1984; Komi et al., 1987), an I-form (Barry and Ahmed, 1986); Ahmed et al., 1987), or an S-form (Schuind et al., 1992). Some of the previous frames and the corresponding working principles were described in the paper of Ravary et al. (2004). Despite wide spreading, these transducers have large dimensions compromising minimally invasive procedures. As an example, the size of the implantable E-form buckle transducer for animal studies is about $9 \times 5 \mathrm{~mm}^{2}$ (Walmsley et al., 1978) and about $34 \times 20 \mathrm{~mm}^{2}$ for human studies (Ravary et al., 2004). Hence, far from being minimally invasive their use is typically restricted to large tissues, such as the Achilles tendon, the anterior cruciate ligament or the patellar tendon (Fleming and Beynnon, 2004; Ravary et al., 2004). Long recovery times (two to three weeks) seem to be necessary for complete healing of the implantation wound (Komi et al., 1987; Gregor et al., 1991; Fukashiro et al., 1993; Komi et al., 1996). They can also modify the natural biomechanical behaviour of the tissue because the frame usually diminishes its length (Markolf et al., 1990). In vivo studies require surgery under local intra-articular anaesthesia (Komi, 1990). Their sensitivity can vary with joint angle, sensor placement and orientation (An et al., 1990; Fleming and Beynnon, 2004). Besides buckle transducers, two other types of SG based transducers can be used to sense force in ligaments and tendons, namely the implantable force transducer (IFT) (Kear and Smith, 1975; Xu et al., 1992; Glos et al., 1993; Fleming et al., 1994; Herzog et al., 1996; Korvick et al., 1996; Markolf et al., 1998; Fleming et al., 1999; Hall et al., 1999; Fleming et al., 2000; Meyer et al., 2004; Bull et al., 2005) and the modified pressure transducer (MPT) (Holden et al., 1994; Holden et al., 1995). The IFT was introduced in 1992 by Xu et al. (1992). Some IFT configurations and the corresponding working principles were described in the paper of Ravary et al. (2004). The IFT is smaller than buckle transducers but the MPT is the smallest. Typical dimensions of the MPT are 3.5-4 mm and 0.5-1.5 mm thick (Ravary et al., 2004). Even so, all of them are much larger than FOS. Like buckle transducers IFT sensitivity may vary with joint angle, sensor placement and orientation (Xu et al., 1992; Holden et al., 1995; Herzog et al., 1996; Fleming et al., 1999). Depending on the calibration protocol results can vary significantly (Herzog et al., 1996). More repeatable results can be obtained using the in situ calibration method proposed by Herzog et al. (1996). Another important constraint is a nonlinear relationship between the compressive load acting on the sensor and the tensile load applied to the tissue (Glos et al., 1993; Holden et al., 1995; Fleming et al., 1999; Fleming et al., 2000). 


\subsection{Fibre optic sensors}

\subsubsection{Intensity modulated sensors: applications}

The first contribution of FOS to measure force of ligaments and tendons was an attempt to reduce errors related to the large dimensions of CS and to minimize subject's complaints. This was pursued in the ex vivo experiment of (Komi et al., 1996) through the use of an intensity modulated sensor. A guiding needle was used to insert the optical fibre (Toray Industries Inc.) in the rabbit common calcaneal tendon mid-substance. It was expected that the tensile load applied to the tendon would produce a compressive load on tendon fibres and bend the optical fibre. The fibre was illuminated by an infrared LED with central wavelength at $820 \mathrm{~nm}$ and the detector was an integrated IC photodiode, as showed in Fig. 7. Strain to force calibration was done using the moment equilibrium condition of a rigid body. Under static conditions a good linear fit was registered between the sensor output and the applied loads. Hysteresis was considered negligible. Under dynamic loading conditions the optical fibre followed the response of a reference SG transducer, despite a time delay of $6.5+2.6 \mathrm{~ms}$ that was measured for the optical fibre response (Komi et al., 1996).

In vivo studies followed that of Komi et al. (1996). The first one was made by Finni et al. (1998) who used the same optical system, with telemetry incorporated, to measure the Achilles tendon force during locomotion. Instead of intra-articular anaesthesia, an anaesthetic cream was applied to the skin surrounding the tendon. Sensor calibration was made in situ, after implantation, using an ankle ergometer to perform isometric plantar flexions (Komi et al., 1996). Similar intensity modulated FOS were used to carry out more in vivo experiments, namely to study the individual muscle contributions to Achilles tendon force (Arndt et al., 1998), leg muscles contributions to perform standardized jumps (Finni et al. 2000), muscle behaviour during jump skills (Finni et al., 2001), the interaction between the lower leg muscles and the Achilles tendon in walking (Ishikawa et al., 2005) and the influence of tendon's creep in sensor behaviour (Muller et al., 2008). However, the validity of previous studies can be questioned in the absence of efforts to identify possible sources of error in estimating tendon forces. In fact and contradicting the original findings of Komi et al., (1996) a nonlinear relationship was observed between the optical fibre output and the tendon force, requiring use of third order polynomials for adequate curve fitting (Erdemir et al., 2002). Hysteresis, cable migration, loading rate, joint angle and skin movement were also pointed as possible sources of error in force prediction. Differences in the loading rate led to root-mean-square (rms) errors less than 17\%. RMS errors due to the combined effects of loading rate and cable migration were less than $32 \%$ (Erdemir et al., 2003). Compared to the C-form transducer the

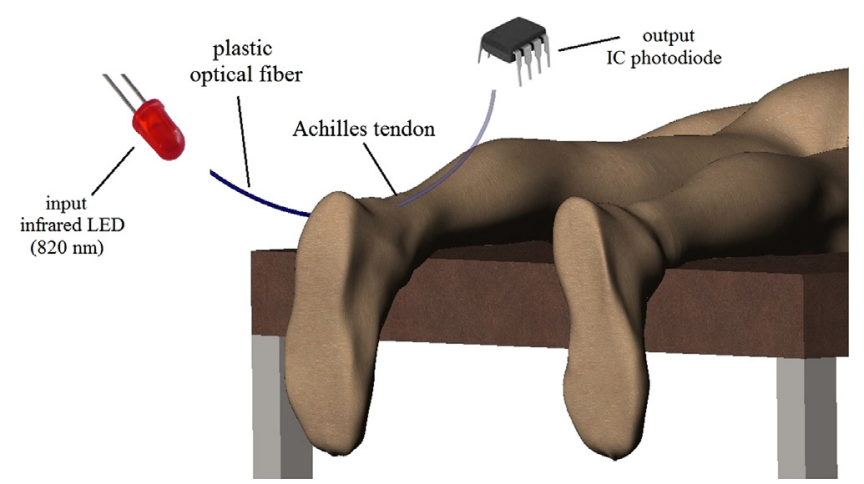

Fig. 7. Schematic representation of the intensity modulated force sensor proposed by Komi et al. (1996).
FOS previously described by Komi et al. (1996) seems to exhibit lower errors in force prediction but larger errors in hysteresis and loading rate (Hall et al., 1999; Erdemir et al., 2002). Tendon creep and skin movement artefacts can also affect the output of the optical signal (Muller et al., 2008). In particular, ex vivo experiments should be conducted without skin, because rms errors in estimating tendon force decreased from $24 \%-81 \%$ of maximum force to $10-33 \%$ after skin removal (Erdemir et al., 2003). Finally, the applied calibration procedures required assumptions concerning the location of joint axes and the length of moment arms, another possible source of error (Fleming and Beynnon, 2004). Recently, Su et al. (2011) presented a miniaturized fibre optic force sensor utilizing Fabry-Pérot interferometry to measure tissue interaction forces in needle-based percutaneous procedures in MRI. The experimental results indicate a gage sensitivity on the order of $40(\mathrm{mV} / \mu \varepsilon)$ of the sensor and a sensing range of $10 \mathrm{~N}$. This sensor achieves high-resolution needle insertion force sensing in a robust and compact configuration in MRI environment. The same type of principle of FOS was used by Liu et al. (2012). The authors designed and built a surgical tool integrated with a miniature force sensor with an outer diameter smaller than $1 \mathrm{~mm}$ for vitreoretinal surgery, based on low-coherence Fabry-Pérot (FP) interferometer interrogated by a fibre-optic common-path phase-sensitive optical coherence tomography (OCT) system (Liu et al., 2012).

\subsubsection{Fibre Bragg gratings for force sensing: working principle}

FBG sensors could represent a step forward in the way of sensing these forces. We have found only two ex vivo studies using them, meaning there is much to be done. For strain measurement, FOS can be based in FBG sensors. For that purpose, strain can be measured and then converted into force values. Considering Hook's law, force (F) and strain are related by:

$\bar{A}=E \varepsilon$

where $A$ represents the cross section of optical fibre and $E$ being its Young modulus.

Combining Eqs. 4 and 5, the shift wavelength can be calculated as:

$\frac{\Delta \lambda_{B}}{\lambda_{B}}=\left(1-p_{e}\right) \frac{F}{E A}$

Pacheco and Bruno (2013) mounted a FBG in a dynamometer and obtained an FBG force sensitivity of $1.36 \mathrm{~nm} / \mathrm{N}$.

\subsubsection{Fibre Bragg gratings for force sensing: applications}

In the study of Vilimek (2008) the force of porcine leg tendons was successfully estimated under loads applied by a tensile machine. It has been argued that FBG measurements are more accurate than those obtained with intensity modulated sensors. FBG sensors were also used in the original study of Goh et al. (2007) with the purpose of measuring the axial load within the menisci of porcine knee joints. A transverse load was applied and to relate it better with the measured axial load, the FBG sensor was placed between uneven layers of carbon-epoxy composites using a buckle configuration (Tjin et al., 2001a; Goh et al., 2007). Calibration was accomplished with a mechanical testing machine and suggested a wavelength/load linear relationship. However, the overall dimensions of the probe $\left(5 \times 5 \mathrm{~mm}^{2}\right)$ compromise its use as a minimally invasive device. Application of multiplexing techniques to produce several in-line FBG sensors could give a more accurate picture of the force transmission along the tissue but this task has still to be done.

FOS were also applied in dental biomechanics. One of the first applications was a mouthpiece system capable of measuring bite forces, with a microbend sensor (Kopola et al., 1995), ranging from 
0 to $1000 \mathrm{~N}$ with a resolution of $10 \mathrm{~N}$. In the original study of Tjin et al. (2001a, 2001b) FBG sensors were applied to measure strain and temperature during positioning of a splint within the mouth and after its placement. The strain sensor was calibrated to measure force using a previously described protocol (Tjin et al., 2001b). Temperature effects were compensated and the accuracy for force and temperature measurement was $0.5 \mathrm{~N}$ and $0.1^{\circ} \mathrm{C}$, respectively (Tjin et al. 2001a, 2001b). More applications in dental biomechanics include use of high-birefringence (HiBi) FBG sensors to measure in vitro orthodontic forces (Milczeswki et al., 2006), and use of bracket polymer photonic crystal fibres (PCF) sensors to measure the forces applied in tooth during realistic orthodontic treatments (Milczewski et al. 2007a, 2007b).

Specific applications for sports and robotic surgery have been also proposed, such as in the case of handgrip devices that were used to measure strength and to evaluate fitness condition. An alternative to conventional dynamometric devices was presented by Paul et al. (2005), incorporating the advantage of assessing individual finger participation in force production. Five FBG sensors were sandwiched between rubber bushings in a cylindrical grip holder. Wavelength shifts were related to the pressure applied by fingers onto the rubber bushing (Paul et al., 2005). Park et al., (2008b) took first steps in the creation of force sensing robot fingers with embedded FBG, to be used in the presence of large magnetic fields. Controlled grasp force during manipulation tasks of small weights $(0.1 \mathrm{kgf})$ was possible to obtain.

Intensity modulated sensors (Polygerinos et al., 2009, 2010) and FBG sensors have already been proposed (Yokoyama et al., 2008; Iordachita et al., 2009; Song et al., 2009; Endosense, 2013) to provide force feedback during robotic assisted minimally invasive surgeries and catheter based operations, such as cardiac catheterization and ablation procedures. An example of a novel application of light intensity-modulated sensors supported by reflective membranes is the RF ablation catheter with force feedback, presented by Polygerinos et al. (2009, 2010). Three plastic optical fibres were aligned inside a plastic catheter in a circular pattern to provide a three axes force sensing system (Fig. 8). The sensor was tested in an artificial blood artery showing a working range of $0-1.1 \mathrm{~N}$, a resolution of $0.04 \mathrm{~N}$ and good dynamic response.

TactiCath $^{\text {TM }}$ is a commercially available solution from Endosense SA. This sensor is composed of three FBG capable of measuring strain of the catheter tip in contact with tissue (Yokoyama et al., 2008; Shah et al., 2010; Thiagalingam et al., 2010). Contact forces along three different directions can be measured with a $10 \mathrm{~Hz}$ frequency and a resolution better than $0.001 \mathrm{kgf}$. Monitoring these forces during catheter based ablation procedures is important because it was demonstrated that the incidence of lesions increases with the catheter force applied to tissue (Yokoyama et al., 2008; Shah et al., 2010; Thiagalingam

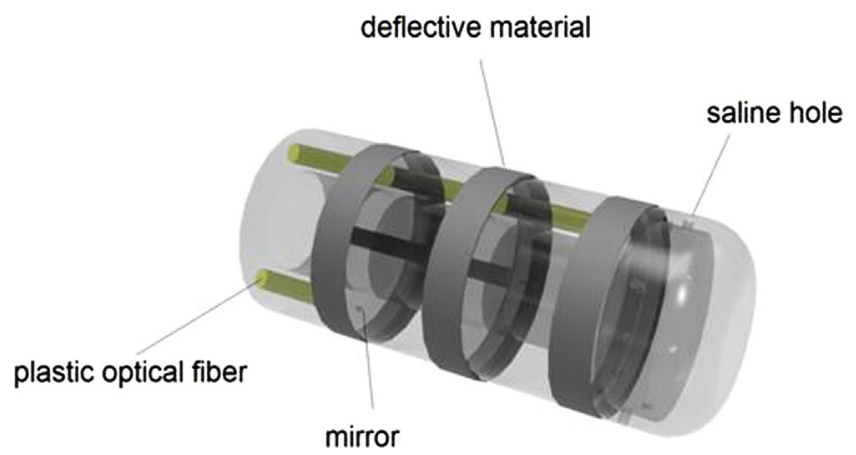

Fig. 8. Schematic drawing of the force sensor proposed by Polygerinos et al. (2009, 2010). et al., 2010). This is important in robotic surgery because it contributes to minimize the lack of haptic feeling from the surgeon (Song et al., 2009, 2011). Also for surgery procedures requiring extremely subtle manoeuvres and forces, usually lower than human perception (Iordachita et al., 2009).

Some advanced clinical procedures requiring MRI environment will benefit from the immunity of FOS systems to MW interference. As in the case of brain function, studied trough functional MRI (fMRI), FOS can be implemented to assess other related functions such as motor function (Tada et al., 2002; Takahashi et al., 2003; Gassert et al., 2006). Additionally, the possibility of combining haptic sensing and optical trackers, developed to trace curves of pertinent anatomical structures (Howe and Matsuoka, 1999), seems a promising field in medicine.

\section{Conclusions}

FOS proven to have advantages compare to CS and a great potential for biomechanical and biomedical applications. Compared to them, they are smaller, easier to implement, minimally invasive, with lower risk of infection, highly accurate, well correlated, inexpensive and multiplexable.

Some research has also been made to demonstrate their ability for in vivo measurements and applications. For in vivo applications, FOS are able to be easily sterilized by autoclave heating or immersion in ethylene oxide, sodium hypochlorite, chloramines $\mathrm{T}$ or peracetic acid. Under sterile conditions, optical fibre will minimize contamination and the risk of infection associated to invasive procedures.

For in vivo measurements when strain values are only required, cross sensitivity of FBG to temperature must be take into account to be compensated with accurate implemented techniques, instead of assuming negligible effects under apparently controlled situations. That is the case for in vivo applications under infectious process or vigorous physical activity, followed by an increase in temperature, or for long term monitoring temperature corrections must be made.

However, nowadays, some set-up implementation obstacles, regarding fibre optic external connections and interrogation systems, make it difficult to use. Probably, this can be one of the major challenges that FOS must overcome, to be possible to commercialize this technology for daily practice.

\section{Conflict of interest statement}

The authors declare no conflict of interest.

\section{Acknowledgements}

This work was supported by the Portuguese Foundation for Science and Technology (FCT), through the fellowship SFRH/BD/ 45130/2008. Project "NORTE-07-0124-FEDER-000058" is financed by the North Portugal Regional Operational Programme (ON.2 O Novo Norte), under the National Strategic Reference Framework (NSRF), through the European Regional Development Fund (ERDF), and by national funds, through the Portuguese funding agency, Fundação para a Ciência e a Tecnologia (FCT).

\section{References}

Aamodt, A., Lund-Larsen, J., et al., 1997. In vivo measurements show tensile axial strain in the proximal lateral aspect of the human femur. J. Orthop. Res. 15 (6), 927-931. 
Ahmed, A.M., Hyder, A., et al., 1987. In-vitro ligament tension pattern in the flexed knee in passive loading. J. Orthop. Res. 5 (2), 217-230.

Al-Fakih, E., Osman, N.A. A., et al., 2012. The use of fiber Bragg grating sensors in biomechanics and rehabilitation applications: the state-of-the-art and ongoing research topics. Sensors 12, 12890-12926.

Alberto, N., Carvalho, L., et al., 2011. "Characterization of different water/powder ratios of dental gypsum using fiber Bragg grating sensors.". Dent. Mater J. 30 (5), 700-706.

Allsop, T., Carroll, K., et al., 2007. Application of long-period-grating sensors to respiratory plethysmography. J. Biomed. Opt. 12 (6), 064003.

Allsop, T., Earthrowl-Gould, T., et al., 2003. Embedded progressivethree-layered fiber long-period gratings for respiratory monitoring. J. Biomed. Opt. 8 (3), 552-558.

An, K.N., Berglund, L., et al., 1990. Direct in vivo tendon force measurement system. J. Biomech. 23 (12), 1269-1271.

Arkwright, J.W., Blenman, N.G., et al., 2009. In-vivo demonstration of a high resolution optical fiber manometry catheter for diagnosis of gastrointestinal motility disorders. Opt. Express 17 (6), 4500-4508.

Arndt, A., Westblad, P., et al., 1999. An in vitro comparison of bone deformation measured with surface and staple mounted strain gauges. J. Biomech. 32 (12), 1359-1363.

Arndt, A.N., Komi, P.V., et al., 1998. Individual muscle contributions to the in vivo Achilles tendon force. Clin. Biomech. 13 (7), 532-541.

Augousti, A.T., Maletras, F.X., et al., 2005. Improved fibre optic respiratory monitoring using a figure-of-eight coil. Physiol. Meas. 26 (5), 585-590.

Augousti, A.T., Maletras, F.X., et al., 2006. Evaluation of cardiac monitoring using fiber optic plethysmography. Ann. Biomed. Eng. 34 (3), 416-425.

Babchenko, A., Khanokh, B., et al., 1999. Fiber optic sensor for the measurement of respiratory chest circumference changes. J. Biomed. Opt. 4 (2), 224-229.

Bach, J.M., Hull, M.L., et al., 1997. Direct measurement of strain in the posterolateral bundle of the anterior cruciate ligament. J. Biomech. 30 (3), 281-283.

Barnes, G.G., Pinder, D.N., 1974. In vivo tendon tension and bone strain measurement and correlation. J. Biomech. 7 (1), 35-42.

Barry, D., Ahmed, A.M., 1986. Design and performance of a modified buckle transducer for the measurement of ligament tension. J. Biomech. Eng.-T ASME 108 (2), 149-152.

Berns, G.S., Hull, M.L., et al., 1992. Strain in the anteromedial bundle of the anterior cruciate ligament under combination loading. J. Orthop. Res. 10 (2), 167-176.

Beynnon, B.D., Fleming, B.C., 1998. Anterior cruciate ligament strain in-vivo: a review of previous work. J. Biomech. 31 (6), 519-525.

Beynnon, B.D., Howe, J.G., et al., 1992. The measurement of anterior cruciate ligament strain in vivo. Int. Orthop. 16 (1), 1-12.

Brown, T.D., Sigal, L., et al., 1986. Dynamic performance characteristics of the liquid metal strain gage. J. Biomech. 19 (2), 165-173.

Bull, A.J., Reilly, P., et al., 2005. A novel technique to measure active tendon forces: application to the subscapularis tendon. Knee Surg. Sport Tr. A 13 (2), 145-150.

Burr, D.B., Milgrom, C., et al., 1996. In vivo measurement of human tibial strains during vigorous activity. Bone 18 (5), 405-410.

Butler, D.L., Guan, Y., et al., 1992. Location-dependent variations in the material properties of the anterior cruciate ligament. J. Biomech. 25 (5), 511-518.

Caler, W.E., Carter, D.R., et al., 1981. Techniques for implementation an in vivo bone strain gage system. J. Biomech. 14 (7), 503-507.

Carvalho, L., Silva, J.C., et al., 2006a. Application of Bragg grating sensors in denta biomechanics. J. Strain Anal. Eng. 41 (6), 411-416.

Carvalho, P., Abe, I., et al., 2006b. FEA and experimental FBG sensing system for the analysis of different dental implant concepts. J. Biomech. 39, S568.

Clark, F., E. Schmidt, et al., Fiber optic blood pressure catheter with frequency response from DC into the audio range. In: Proceedings of the Nat Elec Conf. E. Jones. McCormick Place, Chicago, IL (1965) 21: 213-216.

Collins, C.C., O'Meara, D., et al., 1975. Muscle tension during unrestrained human eye movements. J. Physiol. 245 (2), 351-369.

Davis, C., Mazzolini, A., et al., 1999. A new sensor for monitoring chest wall motion during high-frequency oscillatory ventilation. Med. Eng. Phys. 21 (9), 619-623.

De Smet, E., Jaecques, S.V., et al., 2008. Effect of strain at low-frequency loading on peri-implant bone (re)modelling: a guinea-pig experimental study. Clin. Oral Implants Res. 19, 733-739.

Draganich, L.F., Vahey, J.W., 1990. An in vitro study of anterior cruciate ligament strain induced by quadriceps and hamstrings forces. J. Orthop. Res. 8 (1) 57-63.

Dziuda, L., Krej, M., et al., 2013a. Fiber Bragg grating strain sensor incorporated to monitor patient vital signs during MRI. IEEE Sens. J. 13 (12), 4986-4991.

Dziuda, L., Skibniewski, F.W., et al., 2013b. Fiber Bragg grating-based sensor for monitoring respiration and heart activity during MRI examinations. J. Biomed. Opt. 15 (5), 057006.

Edwards, R.G., Lafferty, J.F., et al., 1970. Ligament strain in the human knee. J. Basic Eng.-T. ASME 38, 131-136.

Endosense. (2013). Retrieved November, 2011, from 〈http://www.endosense.com/ professionals/clinical-trials.html

Enson, Y., Briscoe, W.A., et al., 1962. In vivo studies with an intravascular and intracardiac reflection oximeter. J. Appl. Physiol. 17 (3), 552-558.

Enson, Y., Jameson, A.G., et al., 1964. Intracardiac oximetry in congenital heart disease. Circulation 29, 499-507.

Erdemir, A., Hamel, A.J., et al., 2003. Fiberoptic measurement of tendon forces is influenced by skin movement artifact. J. Biomech. 36 (3), 449-455.

Erdemir, A., Piazza, J.P., et al., 2002. Influence of loading rate and cable migration on fiberoptic measurement of tendon force. J. Biomech. 35, 857-862.
Erickson, A., B. Beynnon, et al., 1988. An in-vivo study of ACL strain in the normal knee during Lachman and Drawer tests. In: Proceedings of the 14th Annual Northeast Bioengineering Conference, Durham, NH, USA.

Fabry, C., Pérot, A., 1896. Measure de petites epaisseurs en valeur absolue. Comptes Rendus 123, 855-858.

Finni, T., Ikegaw, S., et al., 2001. In vivo behavior of vastus lateralis muscle during dynamic performances. Eur. J. Sport Sci. 1 (1), 1-13.

Finni, T., Komi, P.V., et al., 2000. In vivo human triceps surae and quadriceps femoris muscle function in a squat jump and counter movement jump. Eur. J. Appl. Physiol. 83 (4), 416-426.

Finni, T., Komi, P.V., et al., 1998. Achilles tendon loading during walking: application of a novel optic fiber technique. Eur. J. Appl. Physiol. 77 (3), 289-291.

Fleming, B.C., Beynnon, B.D., 2004. In vivo measurement of ligament/tendon strains and forces: a review. Ann. Biomed. Eng. 32 (3), 318-328.

Fleming, B.C., Beynnon, B.D., et al., 1994. Determination of a zero strain reference for the anteromedial band of the anterior cruciate ligament. J. Orthop. Res. 12 (6), 789-795.

Fleming, B.C., Cresswell, A., et al., 2002. Strain in the Achilles tendon during isometric contractions of the human triceps surae. Orthop. Res. Soc. 27, 647.

Fleming, B.C., Good, L., et al., 1999. Calibration and application of an intra-articular force transducer for the measurement of patellar tendon graft forces: an in situ evaluation. J. Biomech. Eng.-T ASME 121 (4), 393-398.

Fleming, B.C., Peura, G.D., et al., 2000. Factors influencing the output of an implantable force transducer. J. Biomech. 33 (7), 889-893.

Fleming, B.C., Renstrom, P.A., et al., 2001. The effect of weightbearing and external loading on anterior cruciate ligament strain. J. Biomech. 34 (2), 163-170.

Fresvig, T., Ludvigsen, P., et al., 2008. Fibre optic Bragg grating sensors: an alternative method to strain gauges for measuring deformation in bone. Med. Eng. Phys. 30 (1), 104-108.

Frias, C., Frazão, O., et al., 2009. Mechanical characterization of bone cement using fiber Bragg grating sensors. Mater Des. 30 (5), 1841-1844.

Frommer, P.L., Ross , J., et al., 1965. Clinical applications of an improved, rapidly responding fiberoptic catheter. Am. J. Cardiol. 15 (5), 672-679.

Fukashiro, S., Komi, P.V., et al., 1993. Comparison between the directly measured achilles tendon force and the tendon force calculated from the ankle joint moment during vertical jumps. Clin. Biomech. 8 (1), 25-30.

Gamble, W.J., Hugenholtz, P.G., et al., 1965. The use of fiberoptics in clinical cardiac catheterization: i. intracardiac oximetry. Circulation 31 (3), 328-343.

Gassert, R., Moser, R., et al., 2006. MRI/fMRI-compatible robotic system with force feedback for interaction with human motion. IEEE/ASME Trans. Mechatron. 11 (2), 216-224.

Glos, D.L., Butler, D.L., et al., 1993. In vitro evaluation of an implantable force transducer (IFT) in a patellar tendon model. J. Biomech. Eng.-T. ASME 115 (4A), 335-343.

Goh, P.K., Fuss, F.K., et al., 2007. Measurement of intrameniscal forces and stresses by two different miniature transducers. J. Mech. Med. Biol. 7 (1), 65-74.

Gregor, R.J., Komi, P.V., et al., 1991. A comparison of the triceps surae and residual muscle moments at the ankle during cycling. J. Biomech. 24 (5), 287-297.

Grillet, A., Kinet, D., et al., 2008. Optical fiber sensors embedded into medical textiles for healthcare monitoring. IEEE Sens. J. 8 (7), 1215-1222.

Gurkan, D., D. Starodubov, et al., 2005. Monitoring of the heartbeat sounds using an optical fiber Bragg grating sensor. IEEE Sensors, Irvine, CA

Hall, G.W., Crandall, J.R., et al., 1999. Rate-independent characteristics of an arthroscopically implantable force probe in the human achilles tendon. J. Biomech. 32 (2), 203-207.

Harrison, D.C., Kapany, N.S., et al., 1966. Fiber optics for continuous in vivo monitoring of oxygen saturation. Am. Heart. J. 71 (6), 766-774.

Haussler, K.K., Bertram, J.E. A., et al., 2001. Segmental in vivo vertebral kinematics at the walk, trot and canter: A preliminary study. Equine. Vet. J. 33 (S33), 160-164.

Henning, C.E., Lynch, M.A., et al., 1985. An in vivo strain gage study of elongation of the anterior cruciate ligament. Am. J. Sport Med. 13 (1), 22-26.

Herrick, W.C., Kingsbury, H.B., et al., 1978. A study of the normal range of strain, strain rate, and stiffness of tendon. J. Biomed. Mater Res. 12 (6), 877-894.

Herzog, W., Hasler, E.M., et al., 1996. In-situ calibration of the implantable force transducer. J. Biomech. 29 (12), 1649-1652.

Holden, J.P., Grood, E.S., et al., 1995. Factors affecting sensitivity of a transducer for measuring anterior cruciate ligament force. J. Biomech. 28 (1), 99-102.

Holden, J.P., Grood, E.S., et al., 1994. In vivo forces in the anterior cruciate ligament: direct measurements during walking and trotting in a quadruped. J. Biomech. 27 (5), 517-526.

Hopkins, H.H., Kapany, N.S., 1954. A flexible fibrescope using static scanning. Nature 173 (4392), 39-41.

Hoshaw, S.J., Fyhrie, D.P., et al., 1997. A method suitable for in vivo measurement of bone strain in humans. J. Biomech. 30 (5), 521-524.

Howe, R.D., Matsuoka, Y., 1999. Robotics for surgery. Annu. Rev. Biomed. Eng. 1 (1), $211-240$.

Hugenholtz, P.G., Gamble, W.J., et al., 1965. The use of fiberoptics in clinical cardiac catheterization: II. in vivo dye-dilution curves. Circulation 31 (3), 344-355.

Hugenholtz, P.G., Wagner, H.R., et al., 1969. Application of fiberoptic dye-dilution technic to the assessment of myocardial function. I. Description of technic and results in 100 patients with congenital or acquired heart disease. Am. J. Cardiol. 24 (1), 79-94.

Hull, M.L., Berns, G.S., et al., 1996. Strain in the medial collateral ligament of the human knee under single and combined loads. J. Biomech. 29 (2), 199-206. 
Iordachita, I., Sun, Z., et al., 2009. A sub-millimetric, $0.25 \mathrm{mN}$ resolution fully integrated fiber-optic force-sensing tool for retinal microsurgery. Int. J. Comput. Assisted Radiol. Surg. 4 (4), 383-390.

Ishikawa, M., Komi, P.V., et al., 2005. Muscle-tendon interaction and elastic energy usage in human walking. J. Appl. Physiol. 99 (2), 603-608.

Jansen, M.O., Schamhardt, H.C., et al., 1998. Mechanical properties of the tendinous equine interosseus muscle are affected by in vivo transducer implantation. J. Biomech. 31 (5), 485-490.

Karam, L. Z., A. P. G. O. Franco, et al., 2011. Evaluating the efficacy and influence of the decontamination and sterilization of FBGs exposed to S. aureus and E. coli. AOP'. In: Proceedings of the International Conference on Applications of Optics and Photonics Braga, Portugal.

Kear, M., Smith, R.N., 1975. A method for recording tendon strain in sheep during locomotion. Acta Orthop. Scand. 46 (6), 896-905.

Keegan, K.G., Baker, G.J., et al., 1992. Evaluation of support bandaging during measurement of proximal sesamoidean strain in horses by use of a mercury strain gauge. Am. J. Vet. Res. 53 (7), 1203-1208.

Kennedy, J.C., Hawkins, R.J., et al., 1977. Strain gauge analysis of knee ligaments. Clin. Orthop. Relat. Res. 129, 225-229.

Komi, P.V., 1990. Relevance of in vivo force measurements to human biomechanics. J. Biomech. 23 (1), 23-34.

Komi, P.V., Belli, A., et al., 1996. Optic fibre as a transducer of tendomuscular forces. Eur. J. Appl. Physiol. 72 (3), 278-280.

Komi, P.V., Salonen, M., et al., 1984. In vivo easurements of Achilles tendon forces in man. Med. Sci. Sport Exer. 16 (2), 165.

Komi, P.V., Salonen, M., et al., 1987. In vivo registration of Achilles tendon forces in man. I. Methodological development. Int. J. Sports Med. 8 (1), 3-8.

Kopola, H.K., Mantyla, O., et al., 1995. Instrument for measuring human biting force. SPIE, Lille, France (P SPIE).

Korvick, D.L., Cummings, J.F., et al., 1996. The use of an implantable force transducer to measure patellar tendon forces in goats. J. Biomech. 29 (4), 557-561.

Ladd, M.E., Quick, H.H., 2000. Reduction of resonant RF heating in intravascular catheters using coaxial chokes. Magn. Reson. Med. 43 (4), 615-619.

Lanyon, L.E., Hampson, W.J., et al., 1975. Bone deformation recorded in vivo from strain gauges attached to the human tibial shaft. Acta Orthop. 46 (2), 256-268.

Lau, D., Chen, Z., et al., 2013. Intensity modulated microbend fiber optic sensor for respiratory monitoring and gating during MRI. IEEE Trans. Biomed. Eng. 60 (9), 2655-2662.

Lekholm, A., Lindström, L.H., 1969. Optoelectronic transducer for intravascular measurements of pressure variations. Med. Biol. Eng. Comput. 7 (3), 333-335.

Lewis, J.L., Lew, W.D., et al., 1982. A note on the application and evaluation of the buckle transducer for the knee ligament force measurement. J. Biomech. Eng.-T. ASME 104 (2), 125-128.

Lídia Carvalho, N.J. Alberto, et al., 2011. In the trail of a new bio-sensor for measuring strain in bone: osteoblastic biocompatibility. Biosens. Bioelectron. 26, 4046-4052.

Lin, J.T., Lane, J.M., 2004. Osteoporosis: a Review. Clin. Orthop. Relat. Res. 425, 126-134.

Liu, X., Iordachita, I.I., et al., 2012. Miniature fiber-optic force sensor based on lowcoherence Fabry-Pérot interferometry for vitreoretinal microsurgery. Biomed. Opt. Exp. 3 (5), 1062-1076.

Markolf, K.L., Gorek, J.F., et al., 1990. Direct measurement of resultant forces in the anterior cruciate ligament. An in vitro study performed with a new experimental technique. J. Bone Joint Surg. Am. 72 (4), 557-567.

Markolf, K.L., Willems, M.J., et al., 1998. In situ calibration of miniature sensors implanted into the anterior cruciate ligament. Part I: strain measurements. J. Orthop. Res. 16 (4), 455-463.

Matsuyama, J., Ohnishi, I., et al., 2006. A new method for measurement of bone deformation by echo tracking. Med. Eng. Phys. 28 (6), 588-595.

McCarthy, B., Hood, W.B., et al., 1967. Fiberoptic monitoring of cardiac output and hepatic dye clearance in dogs. J. Appl. Physiol. 23 (5), 641-645.

Meyer, D.C., Jacob, H.A. C., et al., 2004. In vivo tendon force measurement of 2-week duration in sheep. J. Biomech. 37 (1), 135-140.

Mignani, A.G., Baldini, F., 1996. Biomedical sensors using optical fibres. Rep. Prog. Phys. 59 (1), 1-28.

Milczeswki, M.S., Silva, J.C., et al., 2006. Measuring orthodontic forces with HiBi FBG sensors. Optical Fiber Sensors (OFS). Optical Society of America: TuE65, Cancún, Mexico.

Milczewski, M.S., Kalinowski, H., et al., 2007a. Orthodontic forces using polymer PCF. SPIE, Napoli, Italy.

Milczewski, M.S., Silva, J.C., et al., 2006. Determination of setting expansion of dental materials using fibre optical sensing. Meas. Sci. Technol. 17 (5), 1152-1156.

Milczewski, M. S., M. Stevenson, et al., 2007b. Exploiting polymer photonic crystal fibre uniqueness: A simple high resolution pressure sensor. In: Proceedings of the 32nd Australian Conference on Optical Fibre Technology (COIN-ACOFT), Melbourne, VIC.

Milgrom, C., Finestone, A., et al., 2004. A comparison of bone strain measurements at anatomically relevant sites using surface gauges versus strain gauged bone staples. J. Biomech. 37 (6), 947-952.

Milgrom, C., Finestone, A., et al., 2000. In vivo strain measurements to evaluate the strengthening potential of exercises on the tibial bone. J. Bone Joint Surg. Br 82-B 4, 591-594.

Miller, J.M., Robins, D., 1992. Extraocular muscle forces in alert monkey. Vision Res. 32 (6), 1099-1113.

Mishra, V., Singh, N., et al., 2010. Fiber Bragg grating sensor for monitoring bone decalcification. Orthop. Traumatol.: Surg. Res. 96 (6), 646-651.
Mishra, V., Singh, N., et al., 2011. Fiber grating sensors in medicine: current and emerging applications. Sensor Actuat A- Phys. 167, 279-290.

Mook, G.A., Osypka, P., et al., 1968. Fibre optic reflection photometry on blood Cardiovasc. Res. 2 (2), 199-209.

Muller, J.H., Scheffer, C., et al., 2008. In-vivo detection of patellar tendon creep using a fibre-optic sensor. Int. J. Med. Eng. Inform. 1, 155-173.

Othonos, A., 1997. Fiber Bragg gratings. Rev. Sci. Instrum. 68 (12), 4309-4341.

Ottevaere, H., M. Tabak, et al., 2001. Monitoring the stress build-up in dental cements: a novel optical characterization technique. In: Proceedings of SPIE Clinical Lasers and Diagnostics, Amsterdam, Netherlands, SPIE.

Ottevaere, H., Tabak, M., et al., 2005. Optical fiber sensors and their application in monitoring stress build-up in dental resin cements. SPIE, Warsaw, Poland (P SPIE).

Pacheco, C.J., Bruno, A.C., 2013. A noncontact force sensor based on a fiber Bragg grating and its application for corrosion measurement. Sensors 13, 11476-11489.

Park, Y.-L., S. Elayaperumal, et al., 2008a. MRI-compatible Haptics: Feasibility of using optical fiber Bragg grating strain-sensors to detect deflection of needles in an MRI environment. In: Proceedings of 16th Scientific Meeting and Exhibition, Toronto, Canada.

Park, Y.-L., S. C. Ryu, et al., 2008b. Fingertip force control with embedded fiber Bragg grating sensors. Robotics and Automation, 2008. ICRA 2008. IEEE Int C on.

Paul, J., Zhao, L., et al., 2005. Fiber-optic sensor for handgrip-strength monitoring: conception and design. Appl. Opt. 44 (18), 3696-3704.

Perusek, G.P., Davis, B.L., et al., 2001. An extensometer for global measurement of bone strain suitable for use in vivo in humans. J. Biomech. 34 (3), 358-391.

Polanyi, M.L., Hehir, R.M., 1962. In vivo oximeter with fast dynamic response. Rev. Sci. Instrum. 33 (10), 1050-1054.

Polygerinos, P., P. Puangmali, et al., 2010. Novel miniature MRI-compatible fiber-optic force sensor for cardiac catheterization procedures. In: Proceedings of IEEE International Conference on Robotics and Automation (ICRA), Anchorage, AK.

Polygerinos, P., T. Schaeffter, et al., 2009. A fibre-optic catheter-tip force sensor with MRI compatibility: A feasibility study. Proceedings of IEEE Eng Medicine and Biology Conference (EMBC 2009), Minneapolis, MN

Ramirez, A., Hood, W.B., et al., 1969. Registration of intravascular pressure and sound by a fiberoptic catheter. J. Appl. Physiol. 26 (5), 679-683.

Ramos, A., Abe, I., et al., 2006. On the use of fiber Bragg sensors to assess temperature and thermal induce strain profiles in cemented hip mantles. J. Biomech. 39 (1), S514.

Rao, Y.J., Webb, D.J., et al., 1997. In-fiber Bragg-grating temperature sensor system for medical applications. J. Lightwave Technol. 15 (5), 779-785.

Ravary, B., Pourcelot, P., et al., 2004. Strain and force transducers used in human and veterinary tendon and ligament biomechanical studies. Clin. Biomech. 19 (5), 433-447.

Ren, L., Song, G., et al., 2007. Fiber Bragg grating displacement sensor for movement measurement of tendons and ligaments. Appl. Opt. 46 (28), 6867-6871.

Rolf, C., Westblad, P., et al., 1997. An experimental in vivo method for analysis of local deformation on tibia, with simultaneous measures of ground reaction forces, lower extremity muscle activity and joint motion. Scand. J. Med. Sci. Spor. 7 (3), 144-151.

Roriz, P., Abe, I., et al., 2011. Intervertebral disc bulging measurement using a fibre Bragg grating sensor. Exp. Mech. 51, 1573-1577.

Roriz, P., Frazão, O., et al., 2013a. Review of fiber-optic pressure sensors for biomedical and biomechanical applications. J. Biomed. Opt. 18 (5), 1-18.

Roriz, P., Ramos, A., et al., 2013b. Fiber optic intensity-modulated sensors:a Review in Biomechanics. Photonic Sensors 2 (4), 315-330.

Salmons, S. 1969. Meeting Report. In: Proceedings 8th International Conference Med Biology Eng, Chicago, USA.

Schuind, F., Garcia-Elias, M., et al., 1992. Flexor tendon forces: in vivo measure ments. J. Hand Surg.-Am. 17 (2), 291-298.

Shah, D.C., Lambert, $H$, et al, 2010. Area under the real-time contact force curve (Force-time integral) predicts radiofrequency lesion size in an in vitro contractile model. J. Cardiovasc. Electr. 21 (9), 1038-1043.

Silvestri, S. and E. Schena, 2011. Optical-fiber measurement systems for medical applications. Optoelectronics: Devices and Applications. P. Predeep. Rijeka, Croatia, InTech: 205-224.

Singh, R., Ranieri , A.J., et al., 1970. Simultaneous determinations of cardiac output by thermal dilution, fiberoptic and dye-dilution methods. Am. J. Cardiol. 25 (5), 579-587.

Song, H., Kim, K., et al., 2011. Development of optical fiber Bragg grating forcereflection sensor system of medical application for safe minimally invasive robotic surgery, Rev. Sci. Instrum. 82 (7), 074301-074309.

Song, H., Kim, K., et al., 2009. Development of optical FBG force measurement system for the medical application. SPIE, Singapore.

Su, H., Zervas, M., et al., 2011. A Miniature MRI-Compatible Fiber-optic Force Sensor Utilizing Fabry-Perot Interferometer. Annual Conference on Experimental and Applied Mechanics. Springer, New York (Uncasville, Connecticut, USA).

Szivek, J.A., Gharpuray, V.M., 2000. Mechanical Testing of Bone and the BoneImplant Interface. CRC Press, Boca Raton.

Szivek, J.A., Roberto, R.F., et al., 2005. In vivo strain measurements from hardware and lamina during spine fusion. J. Biomed. Mater. Res. B Appl. Biomater. 75, 243-250.

Szivek, J.A., Roberto, R.F., et al., 2002. An implantable strain measurement system designed to detect spine fusion: Preliminary results from a biomechanical in vivo study. Spine 27 (5), 487-497.

Tada, M., S. Sasaki, et al., 2002. Development of an optical 2-axis force sensor usable in MRI environments. In: Proceedings of IEEE Sensors, 2002, Orlando, Florida. 
Takahashi, N., M. Tada, et al., 2003. An optical 6-axis force sensor for brain function analysis using fMRI. In: Proceedings of IEEE International Conference Sensors, Toronto, Canada.

Talaia, P., Ramos, A., et al., 2007. Plated and intact femur strains in fracture fixation using fiber Bragg gratings and strain gauges. Exp .Mech. 47 (3), 355-363.

Thiagalingam, A., D’Avila, A., et al., 2010. Importance of catheter contact force during irrigated radiofrequency ablation: Evaluation in a porcine ex vivo model using a force-sensing catheter. J. Cardiovasc. Electr. 21 (7), 806-811.

Tiwari, U., Mishra, V., et al., 2011. Fiber Bragg grating sensor for measurement of impact absorption capability of mouthguards. Dent. Traumatol. 27 (4), 263-268.

Tjin, S.C., Hao, J., et al., 2001a. A pressure sensor using fiber Bragg grating. Fiber Integrated Opt. 20 (1), 59-69.

Tjin, S.C., Tan, Y., et al., 2001b. Recording compliance of dental splint use in obstructive sleep apnoea patients by force and temperature modelling. Med. Biol. Eng. Comput. 39 (2), 182-184.

Tyson, J., Schmidt, T., et al., 2002. Biomechanics deformation and strain measurements with 3d image correlation photogrammetry. Exp. Techniques 26 (5), 39-42.

Vilimek, M., 2008. Using a fiber Bragg grating sensor for tendon force measurements. J. Biomech. 41 (1), S511 (-S511).

Vlannderen, E., Conza, N.E., et al., 2005. Low back pain, the stiffness of the sacroiliac joint: a new method using ultrasound. Ultrasound Med. Biol. 31 (1), 39-44.

Walmsley, B., Hodgson, J.A., et al., 1978. Forces produced by medial gastrocnemius and soleus muscles during locomotion in freely moving cats. J. Neurophysiol. 41, 1203-1216.

Wehrle, G., Nohama, P., et al., 2001. A fibre optic Bragg grating strain sensor for monitoring ventilatory movements. Meas. Sci. Technol. 12 (7), 805-809.
Whitney, R.J., 1953. The measurement of volume changes in human limbs. J. Physiol. 121, 1-27.

Xu, M.G., Archambault, J.L., et al., 1994. Discrimination between strain and temperature effects using dual-wavelength fibre grating sensors. Electron. Lett. 30 (13), 1085-1087.

Xu, W.S., Butler, D.L., et al., 1992. Theoretical analysis of an implantable force transducer for tendon and ligament structures. J. Biomech. Eng.-T ASME 114 (2), $170-177$.

Yang, P.F., Brüggemann, G.-P., et al., 2011. What do we currently know from in vivo bone strain measurements in humans? J. Musculoskelet. Neuronal. Interact. $11(1), 8-20$.

Yokoyama, K., Nakagawa, H., et al., 2008. Novel contact force sensor incorporated in irrigated radiofrequency ablation catheter predicts lesion size and incidence of steam pop and thrombus. Circ.: Arrhythm. Electrophysiol. 1 (5), 354-362.

Yu, F.T. S., Shizhuo, Y. (Eds.), 2002. Fiber optic sensors. Marcel Dekker, Inc., New York.

Zawawi, M.A., O'Keffe, S., et al., 2013. Intensity-modulated fiber optic sensor for health monitoring applications: A comparative review. Sens. Rev. 33 (1), 57-67. van Brakel, A., 2005. Blood pressure manometer using a twin Bragg grating FabryPerot interferometer. SPIE, Beijing, China (P SPIE).

van Weeren, P.R., Jansen, M.O., et al., 1992. A kinematic and strain gauge study of the reciprocal apparatus in the equine hind limb. J. Biomech. 25 (11), $1291-1301$.

Šprager, S., Zazula, D., 2013. Detection of heartbeat and respiration from optical interferometric signal by using wavelet transform. Comput. Methods Programs Biomed. 111 (1), 41-51. 